\title{
Navigating Mental Models of Risk and Uncertainty within the Ocean Forecast System: An Oregon Case Study
}

\author{
JESSICA KUONEN \\ College of Earth, Ocean, and Atmospheric Sciences, Oregon State University, Corvallis, Oregon \\ FLAXEN CONWAY \\ College of Liberal Arts, Oregon State University, and Oregon Sea Grant, Corvallis, Oregon \\ TED STRUB \\ College of Earth, Ocean, and Atmospheric Sciences, Oregon State University, Corvallis, Oregon
}

(Manuscript received 30 May 2018, in final form 29 January 2019)

\begin{abstract}
This case study explores how to add value to regional ocean condition forecast information by bringing awareness to the processes that govern decision-making and outcomes within the system. A modified mental models research approach is applied to examine differences and similarities in perceptions of risk and comfort with uncertainty between two interdependent communities, the ocean "data provider" and "end user," and how these perceptions impact accessibility and usefulness of data products. In this study, data providers are academic and agency scientists from institutions that provide ocean condition forecasts to public end users $(n=17)$. End users are members of the Oregon commercial-fishing community $(n=16)$. Comparisons reveal key differences and similarities related to the nature of each profession that impact perceptions of scale in time and space and reveal the ways that cumulative and intersecting risks and uncertainties act as key drivers in decision-making. Implications for expanding the current understanding of how ocean forecasts are produced and used include 1) highlighting the value of optimizing ocean forecast delivery tools based on end-user needs and information-seeking processes already in place, 2) identifying structural and cultural barriers within the data-provider network that prevent them from doing so, and 3) demonstrating the value of learning about both producers and users of scientific information and suggesting potential ways to structure cooperation and strengthen relationships between them by working toward a common desired outcome.
\end{abstract}

\section{Introduction}

Integrated coastal observing and modeling systems have substantially advanced the quality of regional ocean forecasts, creating a need to transform these activities into products that can serve end users outside the scientific community (Flemming 2002; IFSOO 2012; Kourafalou et al. 2015; National Academies of Sciences, Engineering, and Medicine 2017b). Ocean forecasts have the potential to serve a diverse set of marineoperations end users including commercial shipping and fishing, recreational boating and fishing, bar pilots,

\footnotetext{
Corresponding author: Jessica Kuonen, jessica.kuonen@gmail. com
}

Coast Guard, and oil spill response though Web-based products (Price and Rosenfeld 2012). A core group of these users, commercial fishermen, regularly risk personal safety, property, and economic loss (Davis 2012; McDonald and Kucera 2007; Thorvaldsen 2013) and are particularly adept at seeking out sources of ocean condition information that include surface temperatures, currents, waves, and wind to inform their decisions (Duncan 2014). Nationwide and in Oregon, commercial fishing is ranked as the most dangerous occupation with a fatality rate that is more than 3 times that of the second most dangerous occupation (logging), with severe weather conditions as a major contributing factor (CDC 2010; National Research Council 1991; USBLS 2010). Commercial fishing is an integral part of Oregon's coastal 
communities and an economic driver for the coast and the state, annually contributing over $\$ 500$ million in personal income (ODFW 2017).

In 2012, researchers worked with members of the commercial-fishing fleet from Newport, Oregon, as part of an effort to document and understand how they make strategic decisions using ocean condition forecasts (Duncan 2014). Findings revealed that fishermen used a variety of data sources yet lacked a single trusted source, and that they were not utilizing the most advanced, publicly available regional forecasts due to the way that scientists presented the information (Duncan 2014). This led to efforts in cooperative product development between scientists and fishermen to create a useful Web interface; however, beyond this case study, a gap remains in transforming ocean forecast data supplied by academic and agency scientists to value-added products that can support decision making in marine operations.

Web interfaces that deliver ocean condition forecast information serve as boundary objects, here defined as objects which bring together scientists and end users, and bridge perceptual and practical differences in understanding between two or more knowledge systems (Huvila et al. 2014; Karsten et al. 2001; Star and Griesemer 1989). Regarding climate forecasting, a large body of literature has focused on understanding how to overcome these differences that prevent the use of scientific information by decision makers, with case studies in agriculture (Crane et al. 2010; Furman et al. 2011), water management (Kirchhoff 2013; Owen et al. 2012), and fire management (Roncoli et al. 2012). For scientific information to be usable, it is consistently recommended that the boundary between producers and users be actively managed through iterative, inclusive, and open communication and translation that promotes mutual understanding between participants (Cash et al. 2003, 2006; Kirchhoff et al. 2013). In their seminal paper, Cash et al. (2003) asserts that decision makers must perceive information to be credible, salient, and legitimate to be usable. Lemos et al. (2012) assert that usability is affected mainly by "three interconnected factors: user's perception of information fit; how new knowledge interplays with other types of knowledge that are currently used by users; and the level and quality of interaction between producers and users" (Lemos et al. 2012, p. 789).

Despite the clear need for iterative engagement between producers and users for information to be useful for decision making, there are several challenges that prevent this from occurring. The intensity of interaction is time-consuming and costly, the process can be slow, and it requires buy-in and prioritization from both parties (Kirchhoff et al. 2013). Furthermore, institutions generally do not invest in boundary functions that are not central to their mission (Buizer et al. 2016). Much of this research has focused on longer-term climate forecasts. Research regarding the integration of near-term weather forecasts into decision-making tends to focus on laypeople's interpretations of uncertainty (Morss et al. 2008; Sivle et al. 2014; Sivle and Kolst $\varnothing ~ 2016$; Zabini 2016) or their interpretations of hurricane or tornado hazard warnings (Demuth et al. 2012), which may not have direct parallels for forecasts of ocean currents and water properties.

This case study describes efforts to bridge the gap between the data-provider and end-user communities in the growing field of near-term regional ocean condition forecasts. It lays the groundwork for future collaborations by learning about each groups' decision-making context through understanding perceptions of risk and comfort with uncertainty. To do this, it frames the problem of how to provide useful ocean condition forecasts as a system, where data providers and end users are interdependent, but the data provider has ultimate power over the tool. This framework assumes that the needs of the end user are better served through understanding how they use the data to make decisions. However, it also recognizes that data providers work within institutional settings that have their own standards and priorities that guide decisions about the information they present and the manner of presentation. This context provides an opportunity to investigate the ways that risk perception and comfort with uncertainty influence decisions about the production of ocean data by data providers and its use in decision making by the end users.

\section{Theoretical framework}

\section{a. Risk perception and comfort with uncertainty}

Uncertainty is part of every decision made by individuals, groups, or institutions and it is approached and communicated differently based on discipline, profession, or problem domain (Smithson 2008). These differences shape the way that each discipline or profession copes with and manages their particular forms of uncertainty (Smithson and Bammer 2008). The expression of uncertainty metrics is standard practice within scientific cultures that produce measurements of a physical quantity, so that those who use it can assess its reliability and compare it to other measurements (JCGM 2008). Ocean forecasts are produced using deterministic ocean models, and therefore cannot provide the kinds of uncertainty metrics that the public is used to seeing with weather 
forecasts that use ensemble modeling. There has been a recent commitment by the weather enterprise regarding the characterization, communication, and perception of weather forecast uncertainty (National Academies of Sciences, Engineering, and Medicine 2017a; National Research Council 2006). While useful to draw upon this work that relates to the general public, it is important to acknowledge that marine-operations end users have their own expertise and unique understanding of forecast uncertainty and risk from ocean use.

Risk perception is the intuitive risk judgment that people rely on to evaluate hazards and is a useful concept for understanding how people make decisions with imperfect information in response to risk and uncertainty (Ropeik 2012; Slovic 1987). Risk perception has been found to impact the uptake of scientific information for use in environmental decision-making (Kirchhoff et al. 2013) and is useful for understanding the context in which decisions are made (Parris et al. 2016). Ocean condition forecasts have value specifically due to the risk and uncertainty that arises from the interaction of two systems: the physics of the coastal ocean and the human communities that work within it. This study assumes that because risk perception and comfort with uncertainty are factors that influence decisionmaking, they are useful dimensions for understanding weather and climate forecast production and use. Because of the considerable differences in the ways that a research scientist and a fishermen might conceive of and orient toward uncertainty in their decision-making (Smithson 2008), we use the term "comfort with uncertainty" in regards to the felt sense of uncertainty (rather than the quantification) and to bridge the divide between discipline- and practice-based conceptions of uncertainty.

\section{b. Mental models}

Methods in the field of risk communication research that seek a deeper understanding of the subjective nature of risk perception have turned toward a better understanding of an individual's mental model of risk (Bostrom et al. 2016; Lazrus et al. 2016; Ropeik 2012; Slovic 2016). Mental models allow for a rich, qualitative description that gives deeper insights into the decisionmaking context than broad, but shallow, quantitative assessments of risk perception (Slovic 2016). They are a way to represent the manner in which individuals organize their thoughts and beliefs about specific topics by capturing cause and effect dynamics and process-thinking (Abel et al. 1998; Craik 1943; Jones et al. 2011); they also influence the way that new information is interpreted (Cone and Winters 2011). Factors such as profession, life experience, and social groups shape an individual's mental model, including their orientation toward uncertainty and risk (Short 1984; Smithson 2008).

Mental models serve to structure and simplify the world and therefore are not complete or accurate representations of reality (Abel et al. 1998; Jones et al. 2011). This simplification carries a cost when people with mental models that "differ in structure, content, focus, and range of concerns" try to communicate or solve problems together (Abel et al. 1998, p. 79). In the ocean condition forecast system context, understanding decision-making in terms of process-thinking for both data providers and end users can allow comparison of mental models to better understand differences and similarities between them.

Mental model studies seeking to understand the factors that affect decision-making and behavior among individual end users and institutional actors in the fields of hurricane and flood risk communication and management commonly use the Morgan et al. (2002) method for mental model elicitation (Bostrom et al. 2016; Lazrus et al. 2016; Wagner 2007; Wood et al. 2012). The Morgan method uses mental model interviews to build an understanding of how a target audience views a system and its risk, then compares it to an expert mental model to identify gaps in understanding that informs risk communications (Morgan et al. 2002). Bostrom et al. (2016) expand the Morgan et al. (2002) method beyond the typical expert/nonexpert domain by considering data providers to be their own system of connected end users, highlighting the usefulness of comparing perceptions and needs within the data-provider community across professional domains.

The current study expands and combines these frameworks by considering data providers and end users to both make expert contributions to risk knowledge within a single ocean condition forecast system. Data providers collect data and model the marine environment; commercial fishermen interpret the risks while navigating and working within that environment. The goal of the present study is not to identify gaps in understanding between the two communities about the same risk, but rather to gain a more holistic understanding of risk knowledge from two communities facing separate but interrelated risks, and to understand the decision-making process of each community as a system united by ocean condition forecasts. Data providers face risks from having an advanced theoretical, yet imperfect, understanding of the physics of the ocean, which can result in providing inaccurate or incomplete forecasts that people use to make decisions. Commercial fishermen face direct risks from the ocean itself to their lives, property, and ability to earn a living. 
The goals of this systems-based approach are to bring awareness to the processes that govern decision-making and outcomes for the system as a whole (Bammer 2008). This paper frames the problem to include and compare both the discipline- and practice-based mental models of ocean forecast data providers and commercial fishermen, respectively. It views these within an interdependent system and asks three broad research questions (RQ)-RQ1: How does the accessibility of ocean forecast data impact the ocean users' comfort with uncertainty, perceived risks, and their ability to cope? RQ2: How does data providers' comfort with uncertainty and perception of risk impact the accessibility of ocean condition forecasts to ocean users? RQ3: What are the main similarities and differences in ocean users' and data providers' comfort with uncertainty and risk around the ocean and ocean condition forecasting?

\section{c. Commercial-fishing community in Oregon}

Because of its ecological relationship to fisheries and the high number of fatalities and personal injury in commercial fishing, there is a large body of literature on risk perception and commercial fishing worldwide framed in the context of occupational safety and fisheries management. Findings from these studies describe risk perception of commercial fishermen to be shaped by various social, political, and economic forces (Bye and Lamvik 2007; Davis 2012; Edvardsson et al. 2011; McDonald and Kucera 2007; Thorvaldsen 2013), although none of these studies takes place in Oregon or the West Coast of the United States.

Oregon's commercial-fishing community is a network of captains, crew, families, fish processors, fish buyers, and gear shops that work together to harvest ocean resources. Commercial fishing off the Oregon coast is physically risky and economically uncertain. Most fulltime active commercial fishermen in the study region target at least two fisheries (often more) to make a living; one of which is likely the nearshore Dungeness crab fishery. They are largely small-scale, independent fishermen working either alone or in groups of two or three (McDonald and Kucera 2007). Time of year and fishery pursued determine where fishermen are in space and what type of gear they use, which in turn impacts the types of hazards they face. There are 3 major ports and 10 smaller ports with working waterfronts located along the Pacific Coast of Oregon, and there are specific hazards associated with entering and leaving port, "crossing the bar," as compared with hazards at sea. The "bar" refers to a shallow region of accumulated sediment at the entrance to a port where incoming wave heights are amplified and may break and create dangerous conditions.
Commercial fishermen seek out weather and ocean condition forecasts to plan fishing trips (Duncan 2014), but little is known about the details of their decisionmaking process or the perceived risks that they are trying to manage beyond a general sense of safety and economic risk (Kite-Powell et al. 2008). This gap in understanding is an opportunity to characterize the nature of the demand for ocean condition forecasts in the modern information environment, in which members of the public can continuously access and discuss new information using digital technologies (Morss et al. 2017). Finally, little is known about how fishermen think about the uncertainty of the forecasts, and whether that plays a role in their decision-making [see Savelli and Joslyn (2012) for an exception]. The conceptualization of forecast uncertainty is particularly important when we think about the risks faced by the data providers.

\section{d. Ocean forecast data providers}

The data-provider community is a network of scientists from different institutions (academic and agency) that carry out different roles to collect and aggregate data and create and distribute data products for dissemination to a range of end users. Forecasts themselves can be a risk to those providing them because of the uncertainty attached to the nature of predictions; however, considerably less is known about perceived risk and other characteristics of the data-provider community tasked with supplying this information (Sarewitz and Pielke 2007) [see Anthony et al. (2014), Bostrom et al. (2016), and Demuth et al. (2012) for exceptions]. Ocean condition forecasts include predictions of a wide array of parameters that include physical factors (e.g., current speed and direction, wave height and periodicity, water temperature at various depths), chemical factors (e.g., salinity), and biological composition (e.g., chlorophyll-A) (Kite-Powell et al. 2008). Ocean condition forecasts are available on a range of time scales, and near-term forecasts with a lead time of 4 to $72 \mathrm{~h}$ are of particular interest to marine operations for planning optimal routes and avoiding dangerous ones (Price and Rosenfeld 2012).

In the Seacast project (Duncan 2014), it was reported that, despite requests by the fishermen, information providers were not comfortable providing longer forecast lead times. Forecast lead time is an important component of "salience" (Cash et al. 2003) or "information fit" (Lemos et al. 2012) of a data product to meet the decision-making need of the end user, but little is known about how the perceived risks experienced by those providing uncertain scientific information may impact salience or information fit. This study recognizes that academic and agency scientists from several institutions make decisions regarding what ocean 
TABLE 1. Interview protocol for each community [modified from Morgan et al. (2002)].

\begin{tabular}{|c|c|}
\hline Commercial-fishing community $^{\mathrm{a}}$ & Data-provider community $^{\mathrm{b}}$ \\
\hline \multicolumn{2}{|c|}{ Open-ended interview questions } \\
\hline $\begin{array}{l}\text { Talk to me about your background as a fisherman (or } \\
\text { as a member of the commercial-fishing } \\
\text { community). } \\
\text { Talk to me about the ocean as an uncertain place. } \\
\text { Talk to me about the ocean as a risky place. }\end{array}$ & $\begin{array}{l}\text { Talk to me about your background and experience in creating/ } \\
\text { disseminating observations/ocean forecast data. }\end{array}$ \\
\hline \multicolumn{2}{|c|}{ Semi-structured interview questions: Exposure } \\
\hline Tell me what creates hazardous ocean conditions. & $\begin{array}{l}\text { What are some of the main barriers to producing accurate and } \\
\text { complete ocean observations/forecasts? } \\
\text { What kinds of uncertainty do you deal with when creating and/ } \\
\text { or disseminating forecasts. } \\
\text { Tell me about the risks you think about in providing that data to } \\
\text { ocean users. }\end{array}$ \\
\hline \multicolumn{2}{|c|}{ Semi-structured interview questions: Effect } \\
\hline How do hazardous ocean conditions impact you? & $\begin{array}{l}\text { How do these uncertainties and risks impact what forecast data } \\
\text { is made available to ocean users? }\end{array}$ \\
\hline $\begin{array}{l}\text { How does the availability of information/forecast } \\
\text { data impact you? }\end{array}$ & $\begin{array}{l}\text { How do these uncertainties and risks impact your work as a } \\
\text { professional or personally? }\end{array}$ \\
\hline \multicolumn{2}{|c|}{ Semi-structured interview questions: Mitigation } \\
\hline $\begin{array}{l}\text { How do you cope with the risks and uncertainties of } \\
\text { ocean conditions before, during, and after your } \\
\text { trips? }\end{array}$ & $\begin{array}{l}\text { What makes you have confidence in the observations/forecasts } \\
\text { that you help to create and disseminate? }\end{array}$ \\
\hline
\end{tabular}

\footnotetext{
${ }^{a}$ This community faces direct risks (to lives, property, and ability to earn a living) from ocean and weather conditions and their uncertainty.

${ }^{\mathrm{b}}$ This community faces indirect risks from providing inaccurate or incomplete forecasts that people subsequently use to make decisions.
}

condition forecast information to provide to public end users and how to present that information, but little is known about this process.

Ocean observation/forecasting is a relatively young field in comparison with weather forecasting and falls under the purview of the National Oceanic and Atmospheric Administration (NOAA) as the scientific agency. The National Weather Service (NWS), The Center for Operational Oceanographic Products and Services (COOPS), and The U.S. Integrated Ocean Observing System (IOOS) are three institutions associated with NOAA as a line office, agency, and a nonfederal partnership, respectively. All three entities have different histories, structures, and missions and play functionally different roles in relationship to NOAA but are tasked with providing ocean forecast information to ocean end users. Each entity has a suite of Web interfaces that provide access to ocean forecast data products; however, each interface or data product is unique.

\section{Methods}

\section{a. Modified mental model elicitation}

Mental model interviews were conducted with individual participants from both communities following a modified protocol developed by Morgan et al. (2002) specific to risk communication that provides a systematic and repeatable interview procedure to elicit an individual's mental model about risk. The Morgan et al. (2002) line of inquiry begins with open-ended questions that allow participants to freely express their views about a risk, followed by more specific, semistructured questions that target the typical risk assessment topics of exposure, effect, and mitigation of risk (Cone and Winters 2011; Morgan et al. 2002). Because data providers and commercial fishermen play functionally different roles in the ocean forecast system, they were not compared along the same dimension of risk knowledge and different interview questions were used for each group (Table 1). Commercial-fishermen interview questions elicited responses about ocean use and ocean forecast use (RQ1), and data-provider questions elicited responses about providing ocean forecast data to end users (RQ2). Interviews for each community were conducted either inperson at a location chosen by the participant, or over the phone, until saturation was reached (Miles et al. 2013).

\section{b. Sampling}

Participants from the commercial-fishing and dataprovider communities were chosen through a combination of modified snowball sampling (Auerbach and Silverstein 2003) starting with key contacts already 


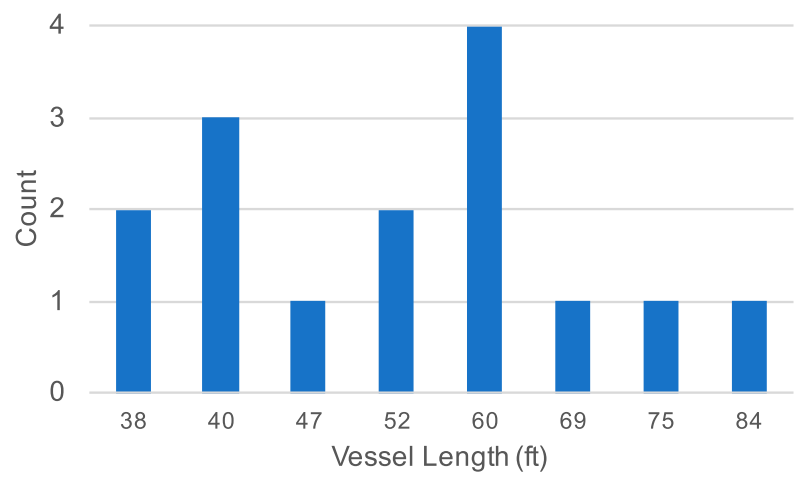

FIG. 1. Range of vessel lengths from fishing-community research participants $(n=15)$, with the industry representative excluded.

engaged in previous work related to this topic (Duncan 2014) and purposeful selection to capture a range of variation within each community (Maxwell 2013).

The commercial-fishing community here includes commercial fishermen from the central Oregon coast and their onshore counterparts, spouses, and representatives of the industry, as the literature suggests that fishermen may play down the presence of actual risk situations as a coping strategy in high-risk work environments (Bye and Lamvik 2007). In total, 16 interviews were conducted with 11 fishermen, 4 fishermen's wives, and 1 industry representative. Seven participants were already engaged in previous work related to this topic, and 9 participants were a result of snowball sampling. Most of these were based out of Newport, the secondlargest port for commercial-fishing landings located along the central Oregon coast. Participants represented the typical fisheries and ranges of gear types (ODFW 2017), fishing vessel lengths (Fig. 1), and ages (Fig. 2).

The data-provider community here represents federal and nonfederal entities associated with NOAA that contribute to publicly available ocean condition forecasts. These entities include agency scientists and managers associated with NWS $(n=4)$ and CO-OPS $(n=2)$ and academic researchers associated with the IOOS $(n=10)$. The goal of this sampling strategy was to gain insight into a range of perspectives across public institutions that provide ocean data and how they might impact the data products. Local data-provider participants included Oregon NWS coastal weather forecasting offices (WFOs), and participants from IOOS West Coast Regional Associations with an emphasis on the Pacific Northwest. Four research participants from the national IOOS and CO-OPS offices in Washington, D.C., were also included. In total, 15 interviews were conducted with 17 members from the data-provider community. Seven participants were already engaged in previous work related to this topic, and 10 participants were a result of "snowball sampling."

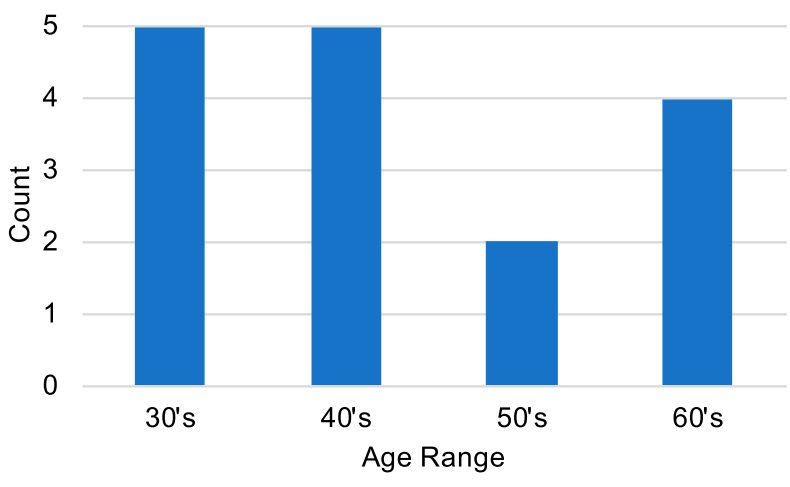

FIG. 2. Fishing-community research participant ages $(n=16)$.

\section{c. Data analysis}

All interviews were recorded, transcribed, and coded for themes using a grounded theory approach (Auerbach and Silverstein 2003) and "MAXQA" software. The traditional method under Morgan et al. (2002) creates conceptual/influence diagrams that express causal connections between concepts, which are then compared to distinguish between experts and nonexperts. The grounded theory approach was deemed appropriate because the purpose of this study is to build a holistic understanding of risk knowledge through a nonhierarchal structure, rather than drawing distinctions that improve communications. Initial open coding identified consistently repeating ideas that were grouped into conceptual themes and then connected back to the research questions in a stepwise process to create a theoretical narrative for each group (Auerbach and Silverstein 2003; Bernard and Ryan 2010; Creswell and Creswell 2017). The data for each community were coded separately; however, four organizing themes were identified and used to structure the comparison between the communities.

\section{Results}

Findings from the commercial-fishing community, the data-provider community, and a comparison between the two are presented in sections $4 \mathrm{a}, 4 \mathrm{~b}$, and $4 \mathrm{c}$, respectively.

\section{a. Commercial fishermen}

With regard to RQ1, characterizing the mental models of participants from the commercial-fishing community conveys the complexity of multiple risks and uncertainties that are constantly evolving, and intersecting based on situational context. Despite the complexity of decisionmaking, perceived risks are clearly understood and relatively consistent among participants, and agree with previous research characterizing ocean and weather conditions as occupational hazard to be worked around (McDonald and Kucera 2007; Thorvaldsen 2013). The inherent uncertainty 
and risk of commercial fishing is a large part of the appeal of the profession and the lifestyle of being a fisherman (Kuonen et al. 2019). There is an acknowledgment that the profession is "not for everyone" and that commercial fishermen are "gamblers at heart," as this quotation from one fishing-community research participant reflects:

I don't know if there's any way to eliminate the risk and if there was I don't think anyone would be really interested in doing it.

Fishermen generally perceived themselves as always working to avoid physical risk-defined here as the risk of injury, death, and damage to the vessel from weather, ocean conditions, or equipment failure-while knowing that the need to remain profitable will sometimes require working under hazardous conditions. Fishermen are motivated to work long hours to remain profitable, in part because of significant overhead costs, and operators must decide when they can "tough it out" through hazardous conditions (Kuonen et al. 2019) (participants commonly referred to all ocean conditions as "weather," and results are reported as such). Decisions about the placement of gear and the need to track it over time add another layer of monetary risk. Because fishing time is valuable, commercial fishermen must choose where and how to set gear efficiently at sea so as not to lose time and effort. Furthermore, there are many thousands of dollars invested in gear that fishermen do not want to lose, as described below:

I don't think of risk as, 'We're going to die' risk, as much as it's like, 'I just lost my crab gear because we had a 28 -foot sea that I didn't foresee coming.' That's risk. [It] washed all my gear on the beach. So, if I don't get it back I lose thousands of dollars.

The cumulative effects from lost gear and lost fishing time compounds the monetary risk, which ripples through the local economy when fishermen cannot deliver product to buyers and processing plants onshore, and contributes to stress. Vessel size and experience of the captain were commonly cited by participants as the most important factors in a fishermen's risk orientation that influence all aspects of decision-making (Kuonen et al. 2019). Smaller vessels of less than $60 \mathrm{ft}(18.3 \mathrm{~m})$ in length have much lower tolerances for wind speeds and wave heights and rely more heavily on forecasts of weather and ocean conditions to move strategically in space (Kuonen et al. 2019).

Forecasts are used for planning when to go, where to go, and how long to stay out; however, the latter two may evolve once a fisherman is at sea, as conditions change. Much of the strategy for commercial fishing depends on the timing and duration of changing weather and ocean conditions and the tide. To maximize fishing time, fishermen will remain at sea as long as possible until the weather or catch limit causes them to return to port. The decision to stop fishing is not always easy:

It's defining that line between what's unsafe and what's just uncomfortable. It can sometimes become blurry, and it can sometimes change unexpectedly, and you find yourself in those spots.

Commercial fishermen perceive forecasts as imperfect and inherently uncertain, because nature is inherently uncertain, yet still rely on them for planning and decision-making. Participants understood that forecast accuracy decreases as lead time of the prediction increases, but they still want to see as far into the future as possible, as this quotation from one fishing-community research participant reflects:

I like as many days as possible. And like I said, it's stupid because it changes so drastically, so rapidly. But I don't know, I like it. It makes me feel better for some reason.

They recognize that forecast accuracy has improved over time, but they do not expect it ever to be perfect (Kuonen et al. 2019). Despite the inaccuracy of forecasts, fishermen perceive forecasters as "doing the best they can" and providing a valuable service in support of their decision-making, as described in the following quotation:

Well, it's the best available science. NOAA Weather puts their best foot forward. They have a model that they follow, and I think it's pretty close actually, within reason. In the fishing industry you kind of know when [weather] is coming. And I think they do a very good job of predicting and it can only get better from here.

Fishermen gain confidence in forecasts through consistent use over time (Kuonen et al. 2019). They compare forecasts with personal observations, real-time information, and forecasts from different sources based on the kind of information they need, and they compare multiple forecasts of the same variable to see how well they agree (Kuonen et al. 2019). These extra layers of interpretation into forecast accuracy were widely reported.

Beyond the use of real-time ocean data and forecasts, participants reported that commercial fishermen are highly adaptive in order to survive in a constantly evolving world. This means constantly monitoring the environment and evaluating their situation using all of their senses: paying attention to the clouds, watching the way buoys lie in the water, feeling the electronics and speed of the boat change with the current, and noticing when the fish stop biting. Although competing with each 
other, they also form a community that communicates and cooperates with each other on the water and with those on land.

Their lives revolve around the weather and so they, their families, and onshore counterparts must be flexible at all times. The way fishermen interact with and interpret weather and ocean-related information is an integral and fully embodied part of their day-to-day fishing process (Thorvaldsen 2013). Their main tools in mitigating risks, in addition to planning and attention to weather forecasts and real-time data, are their faith in their boats, experience, and composure under pressure. These findings are consistent with other risk perception and risk management research for the fishing community in other parts of the world (McDonald and Kucera 2007; Thorvaldsen 2013). For more detailed information on specific ocean hazards and how forecasts are accessed and used for planning and decision-making, see the companion paper by Kuonen et al. (2019).

\section{b. Data providers}

With regard to RQ2, characterizing the mental models of participants from the data-provider community revealed the distinct ways that data flows between members within the scientific community with relative ease and low perceived risk when compared with end users outside the scientific community. There is comfort throughout the scientific data-provider community with the standardized operating procedures (SOPs), formalized procedures for quality assurance and quality control (QA/QC), and documentation of metadata to ensure that data quality is consistent. When scientific researchers and managers use data for analysis, data providers expect the process of academic peer review to somewhat mitigate the risk of misuse by other scientists. However, just as winds, waves, and currents are not hazards until humans interact with them, ocean condition forecasts are not a source of risk until they are put into use for decision-making. For the purposes of this research, the term "application risk" will be used to refer to the perceived risk to the data provider when forecasts are used for decision-making, especially by end users outside the scientific community. Data providers are more uncomfortable with end users who are less familiar with scientific data and perceive them as a higher risk because of the potential for misuse and misunderstanding of data. This is not universal. Participants reported that risk perception and comfort with uncertainty vary within this community depending on institution and role within an institution, and even between individuals with similar roles.

Application risk impacts both the data providers and the end users, but in different ways depending on the context of the decision. High-stakes decisions carry with them the risk of safety, economic, and environmental consequences for the decision-maker, a loss of trust and credibility for the data provider, and in some cases potential liability implications for the initial modelers. Lower-stakes decisions can result in a sense of frustration by the decision-maker, and a loss of trust and credibility for the data provider. Disruptions to data streams, for reasons ranging from impaired sensors to computer software upgrades, can impact accessibility and damage trust, particularly when end users have come to rely on certain data products. Miscommunication that results in a loss of trust or credibility was particularly salient for NWS WFO meteorologists, as they produce warnings in addition to forecasts, with the risk being that the warning or forecast would not be interpreted the way the forecaster intended, as this quotation reflects:

Communicating and maintaining trust: I'm always afraid that I'm not expressing it correctly; that my wording is not going to be right.

All WFO forecasters participating in the study referred to the risk of "cry-wolf syndrome," when a hazardous forecast or warning is issued but the hazards do not materialize. The impact to end users can range from minor inconveniences to major economic consequences; this is confirmed in interviews with fishermen, with the added risk that end users are less likely to trust future forecasts or take action with future warnings. Participants reported that many data providers are concerned with end users making "bad" decisions or might not understand the limitations of the data, as described in the following quotation regarding a real-time data source:

There's always the risk that measurements are imperfect, and someone will act on them without having the same kind of filter in their mind like I do and not recognize if something is junk.

Recalling a somewhat negative experience, one participant described a time when an end user from industry drew inferences that were not appropriate based on the spatial scale of a historical dataset:

What that story taught me is that once you put something out there it can be used for purposes that you and I both know it's not supposed to be used for. But how do you anticipate what people could be using it for, and [how does one] prevent these mistakes from happening?

These distinctions impact the process through which data providers manage and cope with application risk and can ultimately impact how and what data are made 
available. Ocean modelers manage application risk in various ways. These can include masking out data in regions where the modelers are less confident, withholding certain variables, or by making plots of data available as images instead of actual numbers in a downloadable format. It was reported that other modelers simply worry less:

That level of comfort will vary between modelers in terms of how they feel about making certain parts of their model forecast available given the level of validation and calibration that they've done and their understanding of the model. PI's [principal investigators] can come to different decisions within similar settings.

Liability was also mentioned as an obvious concern, although there was also a sense of ambiguity about liability protections through the institution and how that would play out in real life. In general, though, participants were more concerned with personal ethical implications than with legal liability. This interpretation is consistent with characterizations of the modern information environment, where the original creators of forecast information have limited control over how it is interpreted and used once it enters the public sphere (Morss et al. 2017). Participants generally preferred to have an open line of communication with end users, and modelers were more comfortable providing data to those with whom they had worked closely and established relationships. Some participants reported that data providers put more emphasis on quantifying uncertainty. However, it is not consistent throughout the community and is challenging with some types of models.

Application risk specifically regarding commercial fishermen as end users varied between data-provider research participants. Some considered them high-risk users, while others viewed them as savvy enough to understand that forecasts are just guidance. Participants that had interacted with commercial fishermen over time felt more confident in them as trusted end users. Marine forecasters at one Oregon WFO that are particularly well connected to the commercial-fishing community had a detailed understanding of how local fishermen experience hazards and interpret forecasts. They gained this knowledge through building personal relationships with members of the commercial-fishing fleet by going down to the docks, attending meetings with the fishermen, and by taking a boater safety class to better understand the risks that they face. The importance of communicating wave steepness and separating out swell waves from wind waves in the forecast (rather than reporting combined seas) is an example of a valuable change that the WFOs have adopted to make the forecasts useful to mariners. While this example is not representative of all WFOs, it does suggest that some individuals find value in iterative engagement with end users (Cash et al. 2006). Interestingly, several non-NWS data-provider research participants associated commercial fishermen as benefiting from fisheries data rather than from daily weather and ocean forecasts. The assumption that commercial fishermen benefit more from fisheries data could be interpreted as a bias of data providers toward regulatory agencies within NOAA based on their mental models that have been influenced from working within scientific institutions (Kaplan and Kaplan 1982).

When referring to the data itself, data-provider participants described the nature of forecast model output as an imperfect representation of reality, idealized and more conceptual than detailed. One ocean modeler participant described how uncertainty in the weather forecasts that are used to initiate ocean models limits how far into the future ocean forecasts run:

[The weather forecasts] are pretty good for three days and when you get beyond that it's less good, so we don't push it beyond that. We probably could go out a week if we really wanted to, but again, you don't.

Other limitations, or known unknowns, in ocean model forecasts reported by participants included underpredicting extreme events or not being able to adequately capture processes at locations that are spatially and temporally dynamic. Furthermore, the bathymetry of channels and estuaries of major river mouths are often modified by dredging or extreme events and the models might not reflect the most recent changes.

Beyond application risk, a key challenge reported by research participants across agencies and academia was that of resources to fund operations. Research participants shared that maintaining buoys and other sensors in the environment is expensive due to the harsh marine environment, and placement of sensors at optimal locations in space is another challenge for the community due to overlap with shipping lanes, fishing grounds, and other marine and coastal activity. Computing capacity and hiring personnel is another added cost. Challenges to integration among the data-provider community arise when individuals or institutions have "different degrees of rigor and experience" or available resources to maintain their sensors, record proper metadata, and conduct QA/QC procedures. Data attribution-giving proper credit to everyone who funded or helped to create a dataset-is often ambiguous and sometimes political, which can potentially prevent data providers from sharing their data within the scientific community and thus can impact what data are made available to end users. 
These findings have begun to highlight some of the structural and cultural barriers within the data-provider community and how different motivations and multiple competing mission goals can lead to different incentives that impact the prioritization of creating useful data products (Buizer et al. 2016). For example, while part of IOOS's mission is to benefit public safety, integration and research have been prioritized over iterative engagement with some high-stakes end users outside of the scientific community. In contrast, the primary goal of NWS WFOs is to benefit public safety, which creates incentive to build relationships with and understand the needs of regional end users. However, a limitation of their federal status is that they lack the flexibility and innovation of IOOS. It was noted by participants in the research community that the academic reward system does not support stepping outside the bounds of academic communication and peer review:

There is no real standard about how to do this, so we're trying to be as conservative as possible as we go. But yet, I think it is our duty as scientists to start to provide this stuff to the public even though it's not perfect... I feel like it's my duty to not just put stuff in academic journals for my whole career. If it's something that can be used, we should start to do that.

This quotation also conveys how the lack of set standards for communication of data outside of the scientific community impacts scientists' comfort with uncertainty. Despite some communication with targeted end-user groups, all modelers expressed some degree of uncertainty about what the exact needs of the end users are and how to best communicate with them.

\section{c. Mental model comparison}

To structure the comparison of the mental models between communities (RQ3), Table 2 summarizes the narrative analysis and presents key differences and similarities between the data-user and data-provider communities. Results are presented by four organizing themes: 1) professional domain, 2) risk perception, 3) time and spatial scale, and 4) managing risk and uncertainty, with main themes (in the same rows as the organizing themes) that either emphasize the differences or provide the basis for the similarities between each community. Bulleted subthemes provide more detail that relates back to the narrative presented in sections $4 \mathrm{a}$ and $4 \mathrm{~b}$. These themes emerged from the data using both inductive codes (i.e., "professional domain" and "time and spatial scale"), and deductive codes guided by the research questions (i.e., "risk perception" and "managing risk and uncertainty") (Bernard and Ryan 2010). The goal of the table is not to create rigid categories that are generalizable to all data providers and users; instead it organizes the results of this research to inform the discussion, recommendations, and conclusions.

\section{1) Professional domain}

"Professional domain" refers to the main factors and challenges that play into decision-making based on the nature of the profession. It provides the clearest differences between groups, with commercial fishermen operating as small businesses in natural resources, and data providers operating as academic and agency scientists and managers in institutional settings (Table 2). The inherent challenges and uncertainties that arise from the intersection of physical, biological, policy, and economic factors occur regardless of whether fishermen have access to forecast data. Data providers operating within an institutional setting must consider how to support operations under budget constraints. Unlike fishermen, they are not compensated for working longer hours or taking more risks. Sometimes there is one clear mission goal or objective; sometimes there are multiple mission goals or objectives that are prioritized in ways that effectively prioritize the end users. Data-provider roles within the institutional setting tend to be highly specialized, which can hinder the collaborative effort required to create useful forecasts. Despite these differences in professional domain, a key similarity is that both groups take on these professional roles to earn a living. Money and efficiency, whether in acquiring adequate funding or maximizing profits, play central roles in the decisionmaking process for each group. However, for data providers they tend to serve as more of a barrier to the creation of useful ocean forecasts; for commercial fishermen, they serve as a motivation to go to sea.

\section{2) RISK PERCEPTION}

Perceived risks for commercial fishermen tend to be clearer and impact them as individuals. For data providers, perceived risks tend to be more abstract and varied, sometimes including the "general public" in addition to themselves as data providers (Table 2). As businessmen operating in the ocean, commercial fishermen constantly navigate the line between monetary and physical risk and reward. The stakes are high, but the risks are relatively clear. Rather than risk and reward, data providers navigate the line between data as an asset or a liability - and there is ambiguity and a general sense of a lack of control over the data once they are placed in the public domain. When data products are useful for people outside of the scientific community, it increases the value of the data and helps to justify the cost of operations; however, it also increases the potential application risk to the data provider. If data are only utilized within the 
TABLE 2. Comparison of mental models of risk and uncertainty between data-user and data-provider communities by organizing theme.

\begin{tabular}{|c|c|c|c|}
\hline \multirow[b]{2}{*}{ Organizing themes } & \multicolumn{2}{|c|}{ Differences } & \multirow[b]{2}{*}{ Similarities (DU and DP) } \\
\hline & Data users (DU) & Data providers (DP) & \\
\hline Professional domain & $\begin{array}{l}\text { - Weather and ocean conditions } \\
\text { - Fish populations } \\
\text { - Regulations; management } \\
\text { - Market forces } \\
\text { - Cost of operations }\end{array}$ & $\begin{array}{l}\text { - Funding } \\
\text { - Organizational mission and } \\
\text { reward system } \\
\text { - Specialized roles } \\
\text { - Politics }\end{array}$ & $\begin{array}{l}\text { Despite different motivations for } \\
\text { work, both parties must acquire } \\
\text { resources to sustain operations: } \\
\text { - Through fishing (DU) } \\
\text { - Through proving cost-benefit } \\
\text { of work (DP) } \\
\text { - Both value efficiency }\end{array}$ \\
\hline Risk perception & $\begin{array}{l}\text { - Risk acceptance } \\
\text { - Monetary: lost fishing time } \\
\text { and gear } \\
\text { - Physical: ocean and weather } \\
\text { hazards, equipment failure, } \\
\text { and vessel size } \\
\text { - Psychological: stress, } \\
\text { exhaustion, morale, forecasts, } \\
\text { and experience }\end{array}$ & $\begin{array}{l}\text { Abstract and public (application } \\
\text { risk) } \\
\text { - Potential losses to DP: trust, } \\
\text { credibility, reputation, and } \\
\text { liability } \\
\text { - Potential losses to DU: safety, } \\
\text { economic, and environmental } \\
\text { - Ambiguous causes of loss: } \\
\text { inaccurate data, } \\
\text { miscommunication, } \\
\text { misapplication, and new } \\
\text { technology }\end{array}$ & $\begin{array}{l}\text { Despite differences in risk, both } \\
\text { parties face intersecting and } \\
\text { cumulative risks and must strike } \\
\text { the right balance between } \\
\text { - Risk and reward (for DU) } \\
\text { - Asset and liability (for DP) }\end{array}$ \\
\hline $\begin{array}{l}\text { Time and spatial } \\
\text { scale }\end{array}$ & $\begin{array}{l}\text { - When to go, where, and for } \\
\text { how long-related to pro- } \\
\text { fessional domain: fish pop- } \\
\text { ulations, regulations, and } \\
\text { market forces } \\
\text { - Marginal events } \\
\text { - Looking forward in time }\end{array}$ & $\begin{array}{l}\text { - Representativeness of local } \\
\text { physical processes } \\
\text { - Extreme events } \\
\text { - Discomfort with high- } \\
\text { resolution space and time } \\
\text { - Looking backward in time }\end{array}$ & $\begin{array}{l}\text { Despite mismatches in spatial and } \\
\text { temporal scales, both parties } \\
\text { recognize } \\
\text { - That forecasts are imperfect } \\
\text { - The value of real-time data } \\
\text { - The dynamic nature of the } \\
\text { ocean } \\
\text { - That most forcing is due to } \\
\text { wind }\end{array}$ \\
\hline $\begin{array}{l}\text { Managing risk and } \\
\text { uncertainty }\end{array}$ & $\begin{array}{l}\text { - Combine forecasts with other } \\
\text { information (physical } \\
\text { observation, buoy data, } \\
\text { communication with each } \\
\text { other, and Coast Guard) } \\
\text { - Vessel maintenance } \\
\text { - Backup plans }\end{array}$ & $\begin{array}{l}\text { - Documentation } \\
\text { - Disclaimers } \\
\text { - Withhold data } \\
\text { - Uncertainty quantification }\end{array}$ & $\begin{array}{l}\text { Because of the understanding of } \\
\text { model limitations, both parties } \\
\text { remain skeptical of model data } \\
\text { and } \\
\text { - Have processes in place to } \\
\text { double check the data } \\
\text { - Value experience } \\
\text { - Rely on communication within } \\
\text { their networks } \\
\text { - Provide feedback to DP when } \\
\text { they see something wrong }\end{array}$ \\
\hline
\end{tabular}

scientific community, there is less of a return on the investment of collecting or creating the data. Participants from both communities reported a struggle to find the balance between either risk and reward or liability and asset, and both groups face intersecting and cumulative risks that cannot be isolated and dealt with independently.

\section{3) TIME AND SPATIAL SCALE}

Both communities often have a mismatch in their perceptions of spatial and temporal scale that is related to the nature of their professional domain. Commercial fishermen tend to operate on a practical scale that is specific to their decision-making; however, data providers tend to think on a more conceptual and statistical scale and are concerned with representing the local physical processes (Table 2). Timing plays a major role for practical decisions in commercial fishing. Fishermen are concerned with what is happening right now or in the future, whereas data providers are often concerned with what has happened in the past when they validate their 
TABLE 3. Key representative quotations representing similarities from data-provider and fishing-community participant interviews for the organizing theme of "time and spatial scale."

\begin{tabular}{|c|c|c|}
\hline Subtheme & Data-provider participant & Fishing-community participant \\
\hline Forecasts as imperfect & $\begin{array}{l}\text { "The risk to us is sort of the moral risk of } \\
\text { making sure that people use these } \\
\text { forecasts with an understanding that } \\
\text { they are flawed, that they are just one } \\
\text { piece of information to be used with } \\
\text { everything else." }\end{array}$ & $\begin{array}{l}\text { "It's a prediction. It's not 'This is what we } \\
\text { know'; it's, 'This is what we're looking } \\
\text { at and this is what we're predicting will } \\
\text { happen.' Most of the time [forecasters] } \\
\text { get it close, but it's not always } \\
\text { completely accurate. You've got to look } \\
\text { at other things too." }\end{array}$ \\
\hline The ocean as dynamic & $\begin{array}{l}\text { "You can't measure everything } \\
\text { everywhere, so that's a problem, } \\
\text { especially in a very spatially dynamic } \\
\text { area like our coast here off of the Pacific } \\
\text { Northwest. . It's very dynamic and very } \\
\text { diverse, and so that makes any } \\
\text { observation a challenge." }\end{array}$ & $\begin{array}{l}\text { "We really don't have the capacity to } \\
\text { study the whole ocean, so we rely on the } \\
\text { information we have. The environment } \\
\text { is so dynamic. It's always changing, so } \\
\text { it's hard to know from one year to the } \\
\text { next, [or] even one month to the next, } \\
\text { how things are going to react and } \\
\text { interact and behave.". }\end{array}$ \\
\hline Trust in, and value of, real-time data & $\begin{array}{l}\text { "Largely the confidence is based on the } \\
\text { validation we've done over the past, } \\
\text { using observations. . I check the model } \\
\text { every day by looking at a bunch of } \\
\text { different buoys." }\end{array}$ & $\begin{array}{l}\text { "The buoys offshore show us what it's } \\
\text { actually doing: not just the prediction } \\
\text { but what it's actually doing, and that } \\
\text { weather is coming our way. I feel like I } \\
\text { have a lot of confidence in that." }\end{array}$ \\
\hline
\end{tabular}

models. Because of the perceived risks, fishermen tend to be more concerned with marginal conditions when the decision is less clear, whereas data providers tend to focus on how well their models represent extreme events.

Despite these differences, there were some key similarities reported between fishermen and data providers when it came to time and spatial scale. Key quotations representing similarities in subthemes are presented in Table 3. Both communities accept that models are imperfect and that accuracy varies in time and space. Dataprovider participants expressed that it was important for data users to know that models are flawed and that other forms of information need to be used. Commercial fishermen participants consistently expressed a clear understanding of model limitations because they physically observed and experienced uncertainty in the forecasts so often. Participants from both communities frequently used the word "dynamic" to describe the ocean and acknowledged the limited capacity to be able to observe and predict it everywhere. Both groups emphasized the value of real-time observations as a trusted source of data.

\section{4) MANAgING RISK AND UNCERTAINTY}

When it comes to managing risk and uncertainty, commercial fishermen focus on preparation and on-thefly procedures, whereas data providers rely more on formalized procedures and documentation (Table 2). Fishermen combine different forecasts with other types of information and focus on what they can control on board their vessels by having back-up plans and redundancies. Fishermen tend to focus on their tools (i.e., forecasts, vessel, and equipment), whereas data providers tend to focus on processes (i.e., SOPs, QA/QC, and documentation of metadata), although both groups use both. Participants from both communities expressed how they maintain a level of skepticism toward the data and have processes in place to double check it against other sources. Both communities value experience and rely on communication within their networks, and they will provide feedback to all sources from which they receive data if they observe that something is in error.

\section{Discussion and recommendations}

Findings indicate several opportunities for improving the ocean condition forecast system. First, by expanding the current understanding of why and how forecasts are used for decision-making, these results highlight the value of ocean condition forecasts to the commercial-fishing community in Oregon and suggest opportunities for improving the way forecasts are created and communicated. Second, expanding current understanding of why and how forecasts are created within the data-provider community highlights the value of reaching end users beyond the scientific community along with a range of individual and institutional challenges that prevent data providers from doing so. Third, principal findings from both communities demonstrate the value of learning about both producers and users of scientific information 
and suggests potential ways to structure cooperation and strengthen relationships between them by recognizing differences, building on similarities, and working toward a common desired outcome.

This study provides descriptive information on how fishermen interact with and interpret weather- and ocean-related information as an integral and fully embodied part of their day-to-day fishing process (Thorvaldsen 2013). The accessibility of ocean forecast data crucially impacts their ability to cope through better planning and more informed decisions at shorter time scales (from hours to days), particularly for smaller vessels. This finding is a departure from previous research regarding risk perception and fishing that suggests that fishermen only rely on scientific information in their analysis of chronic, long-term risk related to the status of the fishery (Booth and Nelson 2014), an assertion that was shared by some data-provider participants in this study. However, forecast data are only one source of information and are mediated by real-time environmental conditions, experience, and information from other fishermen; this situation is analogous to farmers' use of weather forecasts (Crane et al. 2010). This research importantly reveals that fishermen do not expect perfection in forecasts but believe that being able to "see" as far into the future as possible can help with planning and alleviate stress.

This new understanding confirms the value of ocean condition forecasts to commercial fishermen; an understanding that could likely be extended to other mariners, and suggests opportunities for improving the way ocean condition forecasts are communicated by integrating forecasts within their existing practices (Thorvaldsen 2013). For example, fishermen and their gear experience multiple interacting environmental forces while at sea in specific locations (e.g., wind speed and direction; wave height, direction, and period; and current speed and direction) in specific locations (e.g., bar crossings and fishing grounds). Thus, a simple Web interface that provides access to near-term forecasts and real-time information for multiple ocean variables for a location in space is useful for decision-making and planning because it aligns with their physical experience.

Previous documentation of ocean forecast use by fishermen was limited to a general understanding of go/no-go decisions, was not regionally specific, and was for the purpose of quantifying the economic benefits of regional ocean observing and forecast systems (Kite-Powell et al. 2008). These findings, based on the principles of risk communication, expand that simplified understanding by highlighting the many challenges of the profession and the role of cumulative risks in decision-making and by documenting times and places of increased risk that reflect the physical, social, and economic environment of Oregon. They lay the groundwork for future studies to characterize the mental models for additional potential end-user groups and for other regions of the United States that have different physical, social, and economic contexts. Note that, while interview participants represented a range of fisheries and vessel sizes from the central Oregon commercial-fishing community, some sectors were missing (such as Pacific whiting). This study may have benefited by speaking with multiple members of all aspects of the commercial-fishing community (e.g., crew members, fish processors, and fish buyers).

It is interesting that the fishermen's need to integrate and combine forecasts and observations of different parameters for decision-making closely aligns with the mission and capabilities of data providers within NOAA; however, the majority of data produced within NOAA is for internal use. Application risk is somewhat abstract, difficult to manage, and impacts the accessibility and usefulness of scientific information in complex ways. This finding adds a new variable to current research regarding usability of science that commonly focuses on the end user and suggests a lack of trust from the data providers in the end user's ability to understand their own limits and capacities.

In this study, when data providers formed relationships and were in communication with end users there was less perceived risk and more trust in the end users to make their own decisions and take ownership for any "bad" results of those decisions. Currently, there is little incentive to learn about the needs of the end users beyond basic visualization preferences through formal feedback. These findings are consistent with research in weather forecast and warning systems that show a clear commitment by scientists to technical advances in modeling and less commitment to processes that ensure products are meaningful to users (Bostrom et al. 2016). They agree with literature that reports that strengthening relationships between data providers and end users through face-to-face interactions over time results in more meaningful data products (Cash et al. 2006; Kirchhoff et al. 2013; Lemos et al. 2012) and can potentially reduce perceived risk by the data provider. Furthermore, the considerable variability in perceived application risk, comfort with uncertainty, and impacts to accessibility to ocean data across institutions and specialized roles within NOAA described in this study warrants future research. It is recommended that these knowledge-production institutions adapt more stringent accountability measures to ensure they are providing the kinds of societal benefits they are claiming when they receive public funds. This is particularly relevant for highly impacted users, such as 
commercial fishermen, who do not always have the resources to actively lobby for their interests in the institutional setting.

This study would have benefited from speaking to equal numbers of participants from the different agencies (IOOS, NWS, CO-OPS) and data-provider positions within agencies (e.g., data collectors, modelers, forecasters, data managers, and leadership roles); however, it was not realistic given time constraints. The interview questions for the data-provider community may have been improved by adding an open-ended question about the risks and uncertainties of the profession more closely matching the open-ended questions for the fishing community. The term "ocean user" was used in interview questions because not all dataprovider interview participants worked directly with fishermen; however, this study may have benefited from defining the term more carefully or using a more specific term such as "mariner."

Characterizing and comparing the similarities and differences between data providers' and end users' mental models of uncertainty and risk shift the question of usefulness and accessibility from being a "data issue" to a "relational issue" that further challenges the assumptions and norms of the data-provider community. Through looking at both sides in nonhierarchical terms, we learned that data providers' perceptions and comfort vary widely and can sometimes lead to a lack of trust in the end user. We also learned that fishermen do not expect perfection, are highly adaptive, and while they employ several methods to assess the accuracy of the forecast, they generally trust that data providers are doing the best they can. This reveals an imbalance, where end users are expected to trust the scientific information they are given but data providers are not necessarily expected to trust end users to make use of scientific information in ways that best serve and fit into their processes. The major difference on the temporal scale of decision-making between the profession of fishing and scientific institutions further adds to disconnect regarding what is useful and accessible.

To gain more trust and improve relationships between these two groups, it is recommended that they focus on similarities outlined in Table 2 and the common desired outcome: improving the forecasts. The genesis for this type of engagement could be cooperative research, where fishermen collect observations from the ocean environment (such measurements are described by data providers as costly and difficult to maintain) and provide feedback to help to validate and improve the models, thus making it a truly interdependent and interacting system. Cooperative environmental monitoring has many potential benefits for both groups, as well as the potential to improve resilience of the system through social and adaptive learning between the communities, which can lead to shorter feedback loops between data providers and end users (Cigliano et al. 2015). Future work can be aimed at validating the mental models of the data providers and end users and structuring cooperation between groups.

In light of the differences in mental models between data providers and end users outlined throughout this research, and the inherent resulting biases (Abel et al. 1998; Kaplan and Kaplan 1982), both communities could be served by a dedicated position for end-user engagement. Note that engagement is different from outreach and education in that it is characterized by more of a two-way, coproduced flow of information. This position could be responsible for coordinating and facilitating exchanges between scientists and end users, remaining accountable to both groups, and systematically identifying and documenting regional end user needs over time, as well as internal institutional barriers to engagement (Safford et al. 2017). This position is referenced in literature as a "boundary spanner" to refer to institutions, groups, or individuals that straddle the divide between information producers and users and produce boundary products that enable communication between these two groups (Guston 2001; Parker and Crona 2012; Safford et al. 2017; Tushman 1997).

\section{Conclusions}

These results suggest that this is an exciting, yet critical, time in optimizing ocean condition forecasting to aid in the decision-making of public end users. By framing the ocean forecast system of data providers and end users as interdependent, this study was able to shift the focus from the data itself to the networks of people that produce it and use it. Interdependence, through the lens of risk perception and comfort with uncertainty, reveals a more complex story by highlighting priorities, challenges, and barriers for both groups beyond the traditional "supply" and "demand" of scientific information (Sarewitz and Pielke 2007).

Scientific research concerned with long-term, climactic change and getting users to incorporate these forecasts into their decision making is helpful. It is important to note that, while fishermen are interested in long-term forecasts for fisheries in the context of a changing environment (Colburn et al. 2016), the forecasts involved in this research are near-term (from hours to days) because that is the scale on which fishermen make decisions. The models discussed here do not give fishermen an idea of how their fishery will change next year; rather, they forecast on a day-to-day basis what to expect on their next attempt to fish. We recommend that helping 
end users make near-term decisions through improved relationships, establishing trust from both sides, and collaborating to improve near-term forecasts will lay the foundation for the types of long-term climactic forecasts that researchers are concerned with. In other words, the usability of near-term forecasts might be a useful predecessor to the usability of long-term climate forecasts.

This study begins to highlight the nature of the gap between research to operations for ocean condition forecasts and the importance of bridging that gap through creating value-added products that are informed by enduser needs. Recommendations moving forward include investment in strengthening relationships between data providers and targeted end users, cooperative research to improve near-term forecasts and decision-making, investment in boundary management to facilitate engagement and to enhance accountability to end users, and a closer examination of how structural and cultural barriers within the ocean forecast community may be inhibiting the uptake of ocean forecast information by marineoperations end users. Investment in understanding the social and cultural contexts of decision-making in the modern information environment (Morss et al. 2017) could have a potentially high return in not only improvement of publicly available data, but for innovation into the private sector of ocean forecasting. Furthermore, strengthening relationships between these groups has the potential to enhance the resilience of the overall ocean forecast system by simultaneously benefiting industry and the scientific enterprise along the nation's coasts.

Acknowledgments. This study was funded by Oregon Sea Grant under Award NA14OAR4170064 (Project R/PSS-02-Strub) from the U.S. Department of Commerce National Oceanic and Atmospheric Administration National Sea Grant College Program and by appropriations made by the Oregon State Legislature. The statements, findings, conclusions, and recommendations are those of the authors and do not necessarily reflect the views of these funders. Additional support was provided from the Oregon State University National Science Foundation Research Traineeship: Risk and Uncertainty Quantification in Marine Science, and from an Oregon Space Grant internship. Many thanks are given to the members of the data-provider community from regional and national offices, and to the commercial-fishing community of the central Oregon coast who participated in this study.

\section{REFERENCES}

Abel, N., H. Ross, and P. Walker, 1998: Mental models in rangeland research, communication and management. Rangeland J., 20, 77-91, https://doi.org/10.1071/RJ9980077.
Anthony, K. E., K. R. Cowden-Hodgson, H. D. O'Hair, R. L. Heath, and G. M. Eosco, 2014: Complexities in communication and collaboration in the hurricane warning system. Commun. Stud., 65, 468-483, https://doi.org/10.1080/10510974.2014.957785.

Auerbach, C., and L. B. Silverstein, 2003: An Introduction to Coding and Analysis: Qualitative Data. New York University Press, 202 pp.

Bammer, G., 2008: Adopting orphans: Uncertainty and other neglected aspects of complex problems. Uncertainty and Risk: Multidisciplinary Perspectives, G. Bammer and M. Smithson, Eds., Routledge, 27-44.

Bernard, H. R., and G. W. Ryan, 2010: Analyzing Qualitative Data: Systematic Approaches. SAGE Publications, $451 \mathrm{pp}$.

Booth, L., and R. Nelson, 2014: The perception of chronic and acute risks in the Northern Ireland fishing industry. Saf. Sci., 68, 41-46, https://doi.org/10.1016/j.ssci.2014.02.021.

Bostrom, A., R. E. Morss, J. K. Lazo, J. L. Demuth, H. Lazrus, and R. Hudson, 2016: A mental models study of hurricane forecast and warning production, communication, and decisionmaking. Wea. Climate Soc., 8, 111-129, https://doi.org/10.1175/ WCAS-D-15-0033.1.

Buizer, J., K. Jacobs, and D. Cash, 2016: Making short-term climate forecasts useful: Linking science and action. Proc. Natl. Acad. Sci. USA, 113, 4597-4602, https://doi.org/10.1073/ pnas.0900518107.

Bye, R., and G. M. Lamvik, 2007: Professional culture and risk perception: Coping with danger on board small fishing boats and offshore service vessels. Reliab. Eng. Syst. Saf., 92, 17561763, https://doi.org/10.1016/j.ress.2007.03.024.

Cash, D. W., W. C. Clark, F. Alcock, N. M. Dickson, N. Eckley, and D. H. Guston, J. Jäger, and R. B. Mitchell, 2003: Knowledge systems for sustainable development. Proc. Natl. Acad. Sci. USA, 100, 8086-8091, https://doi.org/10.1073/pnas.1231332100.

, J. C. Borck, and A. G. Patt, 2006: Countering the loadingdock approach to linking science and decision making: Comparative analysis of El Niño/Southern Oscillation (ENSO) forecasting systems. Sci. Technol. Human Values, 31, 465-494, https://doi.org/10.1177/0162243906287547.

CDC, 2010: Commercial fishing deaths-United States, 2000-2009. Centers for Disease Control and Prevention Morbidity and Mortality Weekly Report, Vol. 59 (No. 27), 842-845, https:// www.cdc.gov/mmwr/PDF/wk/mm5927.pdf.

Cigliano, J. A., R. Meyer, H. L. Ballard, A. Freitag, T. B. Phillips, and A. Wasser, 2015: Making marine and coastal citizen science matter. Ocean Coastal Manage., 115, 77-87, https://doi.org/ 10.1016/j.ocecoaman.2015.06.012.

Colburn, L. L., M. Jepson, C. Weng, T. Seara, J. Weiss, and J. A. Hare, 2016: Indicators of climate change and social vulnerability in fishing dependent communities along the eastern and Gulf coasts of the United States. Mar. Policy, 74, 323-333, https://doi.org/10.1016/j.marpol.2016.04.030.

Cone, J., and K. Winters, 2011: Mental models interviewing for more-effective communication: A primer. Oregon Sea Grant Rep. ORESU-H-11-002, 12 pp., https://seagrant.oregonstate. edu/sgpubs/mental-models-interviewing-more-effectivecommunication.

Craik, K. J., 1943. The Nature of Explanation. Cambridge University Press, $136 \mathrm{pp}$.

Crane, T. A., C. Roncoli, J. Paz, N. Breuer, K. Broad, K. T. Ingram, and G. Hoogenboom, 2010: Forecast skill and farmers' skills: Seasonal climate forecasts and agricultural risk management in the southeastern United States. Wea. Climate Soc., 2, 44-59, https://doi.org/10.1175/2009WCAS1006.1. 
Creswell, J. W., and J. D. Creswell, 2017: Research Design: Qualitative, Quantitative, and Mixed Methods Approaches. SAGE Publications, $273 \mathrm{pp}$.

Davis, M. E., 2012: Perceptions of occupational risk by US commercial fishermen. Mar. Policy, 36, 28-33, https://doi.org/ 10.1016/j.marpol.2011.03.005.

Demuth, J. L., R. E. Morss, B. H. Morrow, and J. K. Lazo, 2012: Creation and communication of hurricane risk information. Bull. Amer. Meteor. Soc., 93, 1133-1145, https://doi.org/ 10.1175/BAMS-D-11-00150.1.

Duncan, C., 2014. Cooperative product development between researchers and commercial fishermen to find applications for ocean condition forecasting technology. M.S. thesis, College of Earth, Ocean, and Atmospheric Sciences, Oregon State University, 193 pp.

Edvardsson, I., D. Tingley, A. Conides, B. Drakeford, and D. Holm, 2011: Fishermen's risk perception in four European countries. Marit. Stud., 10 (1), 139-159.

Flemming, N. C., 2002: Strategic planning for operational oceanography. Ocean Forecasting: Conceptual Basis and Applications, N. Pinardi and J. Woods, Eds., Springer, 1-17.

Furman, C., C. Roncoli, T. Crane, and G. Hoogenboom, 2011: Beyond the "fit": Introducing climate forecasts among organic farmers in Georgia (United States). Climatic Change, 109, 791-799, https://doi.org/10.1007/s10584-011-0238-y.

Guston, D. H., 2001: Boundary organizations in environmental policy and science: An introduction. Sci. Technol. Human Values, 26, 399-408, https://doi.org/10.1177/016224390102600401.

Huvila, I., T. D. Anderson, E. H. Jansen, P. McKenzie, L. Westbrook, and A. Worrall, 2014: Boundary objects in information science research: An approach for explicating connections between collections, cultures and communities. Proc. Amer. Soc. Info. Sci. Technol., 51, 1-4, https://doi.org/ 10.1002/meet.2014.14505101003.

IFSOO, 2012. A Framework for Ocean Observing. UNESCO Integrated Framework for Sustained Ocean Observing Rep. IOC/INF-1284, 25 pp., https://doi.org/10.5270/OceanObs09-FOO.

JCGM, 2008: Evaluation of measurement data-Guide for the expression of uncertainty in measurement. Joint Committee for Guides in Metrology Doc., 120 pp., https://www.bipm.org/ utils/common/documents/jcgm/JCGM_100_2008_E.pdf.

Jones, N., H. Ross, T. Lynam, P. Perez, and A. Leitch, 2011: Mental models: An interdisciplinary synthesis of theory and methods. Ecol. Soc., 16, 46, https://doi.org/10.5751/ES-03802-160146.

Kaplan, S., and R. Kaplan, 1982: Cognition and Environment: Functioning in an Uncertain World. Praeger, 287 pp.

Karsten, H., K. Lyytinen, M. Hurskainen, and T. Koskelainen, 2001: Crossing boundaries and conscripting participation: Representing and integrating knowledge in a paper machinery project. Eur. J. Info. Syst., 10, 89-98, https://doi.org/10.1057/ palgrave.ejis. 3000395 .

Kirchhoff, C. J., 2013: Understanding and enhancing climate information use in water management. Climatic Change, 119, 495-509, https://doi.org/10.1007/s10584-013-0703-x.

_ M. C. Lemos, and S. Dessai, 2013: Actionable knowledge for environmental decision making: Broadening the usability of climate science. Annu. Rev. Environ. Resour., 38, 393-414, https://doi.org/10.1146/annurev-environ-022112-112828.

Kite-Powell, H., C. Colgan, and R. Weiher, 2008: Estimating the economic benefits of regional ocean observing systems. Coast. Manage., 36, 125-145, https://doi.org/10.1080/08920750701868002.
Kourafalou, V. H., and Coauthors, 2015: Coastal ocean forecasting: System integration and evaluation. J. Oper. Oceanogr., 8 (Supp. 1), s127-s146, https://doi.org/10.1080/1755876X.2015.1022336.

Kuonen, J., F. Conway, and P. T. Strub, 2019: Relating ocean condition forecasts to the process of end-user decision making: A case study of the Oregon commercial fishing community. Mar. Technol. Soc., 53, 53-66, https://doi.org/10.4031/MTSJ.53.1.1.

Lazrus, H., R. E. Morss, J. L. Demuth, J. K. Lazo, and A. Bostrom, 2016: "Know what to do if you encounter a flash flood": Mental models analysis for improving flash flood risk communication and public decision making. Risk Anal., 36, 411-427, https://doi.org/10.1111/risa.12480.

Lemos, M. C., C. J. Kirchhoff, and V. Ramprasad, 2012: Narrowing the climate information usability gap. Nat. Climate Change, $\mathbf{2}$, 789-794, https://doi.org/10.1038/nclimate1614.

Maxwell, J. A., 2013. Qualitative Research Design: An Interactive Approach. SAGE Publications, 232 pp.

McDonald, M. A., and K. L. Kucera, 2007: Understanding nonindustrialized workers' approaches to safety: How do commercial fishermen "stay safe"? J. Saf. Res., 38, 289-297, https:// doi.org/10.1016/j.jsr.2006.10.009.

Miles, M. B., A. M. Huberman, and J. Saldana, 2013: Qualitative Data Analysis. 3rd ed. SAGE Publications, 408 pp.

Morgan, M. G., C. J. Atman, and A. Bostrom, 2002: Risk Communication: A Mental Models Approach. Cambridge University Press, $351 \mathrm{pp}$.

Morss, R. E., J. L. Demuth, and J. K. Lazo, 2008: Communicating uncertainty in weather forecasts: A survey of the U.S. public. Wea. Forecasting, 23, 974-991, https://doi.org/10.1175/ 2008WAF2007088.1.

_ _ and Coauthors, 2017: Hazardous weather prediction and communication in the modern information environment. Bull. Amer. Meteor. Soc., 98, 2653-2674, https://doi.org/10.1175/ BAMS-D-16-0058.1.

National Academies of Sciences, Engineering, and Medicine, 2017a: Integrating Social and Behavioral Sciences within the Weather Enterprise. National Academies Press, 198 pp., https://doi.org/10.17226/24865.

_ 2017b: Sustaining Ocean Observations to Understand Future Changes in Earth's Climate. National Academies Press, 150 pp., https://doi.org/10.17226/24919.

National Research Council, 1991: Fishing Vessel Safety: Blueprint for a National Program. The National Academies Press, 308 pp., https://doi.org/10.17226/1622.

- 2006: Completing the Forecast: Characterizing and Communicating Uncertainty for Better Decisions Using Weather and Climate Forecasts. The National Academies Press, 124 pp., https://doi.org/10.17226/11699.

ODFW, 2017: Oregon's Ocean Commercial Fisheries. Oregon Department of Fish and Wildlife Doc., 9 pp., http://www.dfw. state.or.us/mrp/docs/Backgrounder_Comm_Fishing.pdf.

Owen, G., J. D. McLeod, C. A. Kolden, D. B. Ferguson, and T. J. Brown, 2012: Wildfire management and forecasting fire potential: The roles of climate information and social networks in the southwest United States. Wea. Climate Soc., 4, 90-102, https://doi.org/10.1175/WCAS-D-11-00038.1.

Parker, J., and B. Crona, 2012: On being all things to all people: Boundary organizations and the contemporary research university. Soc. Stud. Sci., 42, 262-289, https://doi.org/10.1177/ 0306312711435833.

Parris, A. S., G. M. Garfin, K. Dow, R. Meyer, and S. L. Close, 2016: Understanding context and risk. Climate in Context: Science 
and Society Partnering for Adaptation, A. Paris et al., Eds., Wiley-Blackwell, 1-2, https://doi.org/10.1002/9781118474785.

Price, H., and L. Rosenfeld, 2012: Synthesis of regional IOOS build-out plans for the next decade. Integrated Ocean Observing System Association Synthesis Doc., 59 pp.

Roncoli, C., N. Breuer, D. Zierden, C. Fraisse, K. Broad, and G. Hoogenboom, 2012: The art of the science: Climate forecasts for wildfire management in the southeastern United States. Climatic Change, 113, 1113-1121, https://doi.org/10.1007/ s10584-012-0526-1.

Ropeik, D., 2012: The perception gap: Recognizing and managing the risks that arise when we get risk wrong. Food Chem. Toxicol., 50, 1222-1225, https://doi.org/10.1016/j.fct.2012.02.015

Safford, H. D., S. C. Sawyer, S. D. Kocher, J. K. Hiers, and M. Cross, 2017: Linking knowledge to action: The role of boundary spanners in translating ecology. Front. Ecol. Environ., 15, 560-568, https://doi.org/10.1002/fee.1731.

Sarewitz, D., and R. A. Pielke, 2007: The neglected heart of science policy: Reconciling supply of and demand for science. Environ. Sci. Policy, 10, 5-16, https://doi.org/10.1016/j.envsci.2006.10.001.

Savelli, S., and S. Joslyn, 2012: Boater safety: Communicating weather forecast information to high-stakes end users. Wea. Climate Soc., 4, 7-19, https://doi.org/10.1175/WCAS-D-1100025.1.

Short, J. F., 1984: The social fabric at risk: Toward the social transformation of risk analysis. Amer. Sociol. Rev., 49, 711-725, https://doi.org/10.2307/2095526.

Sivle, A. D., and S. D. Kolst $\varnothing$, 2016: Use of online weather information in everyday decision-making by laypeople and implications for communication of weather information. Meteor. Appl., 23, 650-662, https://doi.org/10.1002/met.1588.

, P. J. Kirkeby Hansen, and J. Kristiansen, 2014: How do laypeople evaluate the degree of certainty in a weather report? A case study of the use of the Web service yr.no. Wea.
Climate Soc., 6, 399-412, https://doi.org/10.1175/WCAS-D-1200054.1.

Slovic, P., 1987: Perception of risk. Science, 236, 280-285, https:// doi.org/10.1126/science. 3563507 .

- 2016: Understanding perceived risk: 1978-2015. Environment, 58, 25-29, https://doi.org/10.1080/00139157.2016.1112169.

Smithson, M., 2008: The many faces and masks of uncertainty. Uncertainty and Risk: Multidisciplinary Perspectives, G. Bammer and M. Smithson, Eds., Routledge, 13-25.

_ , and G. Bammer, 2008: Coping and managing under uncertainty. Uncertainty and Risk: Multidisciplinary Perspective, G. Bammer and M. Smithson, Eds., Routledge, 321-333.

Star, S. L., and J. R. Griesemer, 1989: Institutional ecology, 'translations' and boundary objects: Amateurs and professionals in Berkeley's Museum of Vertebrate Zoology, 190739. Soc. Stud. Sci., 19, 387-420, https://doi.org/10.1177/ 030631289019003001

Thorvaldsen, T., 2013: The importance of common sense: How Norwegian coastal fishermen deal with occupational risk. Mar. Policy, 42, 85-90, https://doi.org/10.1016/j.marpol.2013.02.007.

Tushman, M. L., 1997: Special boundary roles in the innovation process. Adm. Sci. Quart., 22, 587-605, https://doi.org/10.2307/ 2392402.

USBLS, 2010: National Census of Fatal Occupational Injuries (CFOI) in 2009. United States Bureau of Labor Statistics, https://www.bls.gov/iif/oshcfoi1.htm.

Wagner, K., 2007: Mental models of flash floods and landslides. Risk Anal., 27, 671-682, https://doi.org/10.1111/j.15396924.2007.00916.x.

Wood, M., D. Kovacs, A. Bostrom, T. Bridges, and I. Linkov, 2012: Flood risk management: US Army Corps of Engineers and layperson perceptions. Risk Anal., 32, 1349-1368, https://doi.org/ 10.1111/j.1539-6924.2012.01832.x.

Zabini, F., 2016: Mobile weather apps or the illusion of certainty. Meteor. Appl., 23, 663-670, https://doi.org/10.1002/met.1589. 